\title{
Socio-Legal Studies in Germany and the UK: Theory and Methods
}

\author{
Jennifer Hendry*, Naomi Creutzfeldt** and Christian Boulanger ${ }^{* * *}$
}

(Received 07 September 2020; accepted 13 September 2020)

\begin{abstract}
This Special Issue considers the situated and contextualized development of socio-legal, or law and society, scholarship within two materially different legal and academic cultures, namely Germany and the United Kingdom, with a view to achieving a better understanding of why and how such differences in understanding and practice have arisen. The contributions are grouped into three themes. The first reflects upon the influence of institutional contexts and scholarly traditions in terms of the development of those approaches that come under the banner of socio-legal studies. The second features contributions that adopt a comparative perspective in terms of selected areas of law, pointing to notably different approaches taken in Germany and the UK, and considering the development of these respective situations. The third looks at the key contemporary trends, theoretical applications, and methodological approaches taken within both countries' socio-legal academic contexts.
\end{abstract}

Keywords: socio-legal studies; sociology of law; legal culture; academic culture; comparative legal studies

\section{A. Introduction}

It is not unusual for an introduction to a socio-legal studies collection to open with acknowledgement that the contours of the discipline - if a discipline it is - are contested. Innately interdisciplinary, there is no universally accepted definition of what constitutes a socio-legal or a law and society approach, or agreement as to what such an approach necessarily encompasses. Instead, law and society scholarship is best defined as "oppositional," due to the manner in which it sets, and has historically set, itself in distinction to doctrinal legal approaches. It is this negative definition that arguably underpins the rude health of socio-legal scholarship: such a broad-church approach lends itself to inclusivity, and those fluid disciplinary contours easily accommodate methodological and theoretical development in both the sociological and the legal fields.

The intent of this Special Issue is neither to reify these contours or to attempt to delimit what is or is not included under the big umbrella of socio-legal studies. Our aim is to consider the situated and contextualized development of socio-legal scholarship within two materially different legal

${ }^{\star}$ Dr. Jennifer Hendry is an Associate Professor in Law and Social Justice at the University of Leeds School of Law, where she is Director of the Centre for Law \& Social Justice.

${ }^{* *}$ Dr. Naomi Creutzfeldt is a Reader in Socio-Legal Studies and teaches public law, comparative law, and socio-legal research methods and theory at the University of Westminster.

${ }^{* * *}$ Dr. Christian Boulanger is a post-doctoral researcher at Humboldt-Universität zu Berlin, where he is also an Associated Researcher in their Law and Society Institute.

${ }^{1}$ Phil Thomas, Christos Boukalas \& Lydia Hayes, The Journal of Law and Society at 40: History, Work, and Prospects, SLSA Newsletter (Socio-Legal Stud. Ass'n, U.K.), Summer 2015, https://onlinelibrary.wiley.com/pb-assets/assets/14676478/ jols_at_40-1509472962000.pdf

(c) The Author(s), 2020. Published by Cambridge University Press on behalf of the German Law Journal. This is an Open Access article, distributed under the terms of the Creative Commons Attribution licence (http://creativecommons.org/licenses/by/4.0/), which permits unrestricted re-use, distribution, and reproduction in any medium, provided the original work is properly cited. 
and academic cultures, namely Germany and the United Kingdom, with a view to achieving a better understanding of why and how such differences in understanding and practice have arisen.

There is currently no published research that adopts a comparative perspective to look at how socio-legal research is undertaken across different academic and legal cultures, and the editors have identified this as a gap in the scholarship. To be clear on this point, while socio-legal studies tend to concern local and national legal issues and features, comparative law looks at legal differences and similarities across jurisdictions. Comparative legal studies considers underlying theoretical and critical issues of relevance and influence, and studies in legal pedagogy focus on teaching and learning - there is little engagement with academic legal cultures, epistemic communities, and institutional drivers and limitations that serve to shape specific and situated sociolegal approaches. This Special Issue is conceived as providing the first engagement with these important issues.

Our explicitly comparative perspective on socio-legal scholarship brings with it its own considerations, not least the interface between socio-legal and comparative legal studies and their respective engagement with critical approaches. With a view to reducing the variables at play, we make a primarily functional comparison of practices concerning socio-legal studies within these two academic legal cultures. ${ }^{2}$ It should be noted at this stage that we employ the term "legal culture" throughout this introduction — and Special Issue - to denote law and legal practice within a particular, often national jurisdictional, social context, and to discuss how aspects of the law are embedded in larger frameworks of social structure. ${ }^{3}$ Our use of the term "academic culture," that is, a network of knowledge-based experts that comprises an epistemic community, ${ }^{4}$ is informed by Friedman's conception of internal legal culture. ${ }^{5}$ Importantly, this conception of a law and society epistemic community can transcend national jurisdictional boundaries and limitations; national law and society research and scholarship communities may be better connected and more coherent, but they are not siloed. In terms of the articles within this Special Issue, we have adopted a light-touch approach to the comparative methodology used, with the result that the Special Issue does not cleave to a single specific comparative approach. Another consideration, in terms of variety across contributor articles, is the jurisdictional differences within the selected countries: the UK has four home nations, across which both law and education differ, often significantly, while Germany is a federal republic where respective federal Länder have jurisdiction over a list of issues detailed in the constitution, including universities and law degrees.

Articles were selected from those presented at a workshop that took place in September 2019 at the Humboldt Universität zu Berlin, supported by the UK Socio-Legal Studies Association (SLSA) and the German Vereinigung für Recht und Gesellschaft. ${ }^{6}$ The presented articles were in turn selected from abstracts submitted to an open call circulated via socio-legal networks in both countries. ${ }^{7}$ This call invited articles that sought to "understand the influence of institutional contexts and scholarly traditions upon the development of those approaches that come under the banner of

\footnotetext{
${ }^{2}$ See Naomi Creutzfeldt, Agnieszka Kubal, \& Fernanda Pirie, Introduction: Exploring the Comparative in Socio-Legal Studies, 12 INT'L J. L. ConTEXT 377 (2016).

${ }^{3}$ David Nelken, Comparative Sociology of Law, in An InTroduction to LAW AND Social Theory 329 (Reza Banakar \& Max Travers eds., 2002).

${ }^{4}$ Jennifer Hendry, The Double Fragmentation of Law: Legal System-Internal Differentiation and the Process of Europeanisation, in 'Integration Through Law, Revisited: The Making of the European Polity 157 (Daniel Augenstein ed., 2013).

${ }^{5}$ Lawrence M. Friedman, The Legal System: A Social Science Perspective (1975).

${ }^{6}$ Further support came from the Recht im Kontext Project and from the Integrative Research Institute Law \& Society, both located at Humboldt's Law Department. We gratefully acknowledge supplemental financial support from the DFG Gottfried Wilhelm Leibniz Prize Funds of Christoph Möllers.

${ }^{7}$ Presentations were selected for their scholarly contribution to reflect a balance in contributions from across German and UK institutions, gender, and career stage.
} 
socio-legal studies," and this core goal remains evident in the articles comprising this issue. Building on this, further stated aims of the workshop were as follows:

- To consider how different academic traditions and institutional contexts have influenced the development of socio-legal research in Germany and the UK;

- To scrutinize theoretical and methodological approaches with a view to exploring similarities and differences in both contexts;

- To start an initial dialogue among participants with a view to forging closer ties across the German and UK socio-legal communities, and to facilitating future connections and collaborations.

This Special Issue remains organized around these aims. Articles in the first section reflect upon the influence of institutional contexts and scholarly traditions in terms of the development of those approaches that come under the banner of socio-legal studies (Introduction, Background, and Development). The second section then features contributions that adopt a comparative perspective in terms of selected areas of law, pointing to notably different approaches taken in Germany and the UK, and considering the development of these respective situations (Historical Socio-Legal Perspectives). Finally, articles in section three look at the key contemporary trends, theoretical applications, and methodological approaches taken within both countries' socio-legal academic contexts (Contemporary Socio-Legal Approaches).

This introductory Article will proceed in four parts. In Part One, we will outline the provisional conceptual mapping of the field undertaken in advance of the September 2019 workshop, with a view to explaining not only how we identified the core strands of our investigation, but also how we discovered that points of contact were neither as obvious nor as consistent as we had originally assumed. Included in this part are our reflections on the challenges raised by the workshop itself, those national and local differences in both practical and interdisciplinary approaches that had us either talking at cross-purposes or encountering unforeseen obstacles. Part Two continues to outline this path of discovery in terms of our drafting of this Special Issue proposal and selecting the articles: our self-reflection on these experiences builds upon insights drawn from a comparative literature review of two collected volumes published in the same year and curated respectively by an editor of this Special Issue. Considered comparison of the contents of these volumestheir theoretical influences and methodological selections-yielded fascinating insight into the respective conditions of contemporary law and society scholarship in Germany and the UK, and assisted us greatly in the selection of the four core issues for consideration throughout this Special Issue: culture (academic and legal); scholars; pedagogy; and environment. Part Three introduces the contributor articles, highlighting the engagement each of these has with the identified core issues, and outlining this Special Issue's timely and important exploration of these questions. The Fourth Part will consider our endeavor into its own contemporary context, not least the continued tragedy of Brexit, but also the hopeful ambition of strengthening ties and connections across these two national law and society research communities.

\section{B. Part One: Conceptual Mapping}

This Special Issue-just as the workshop that it is a result of - is an exercise in academic reflexivity. On the one hand, the research questions and aims for the workshop are in themselves part of the research process creating its own data. For example, we noticed that our expectations about submissions and presentations at the workshop in comparison to what happened on the day were different. On the other hand, these expectations and the questions we ask are evidently connected to our own academic socialization and intellectual identity, and as such, can be seen as "data"; it is even more clear that this applies if the research questions are located at a "meta" level 
(research about research). In this regard, then, this exercise in "conceptual mapping" should be read as our attempt to chart the more commonly used concepts, theories, and methods - the discipline's own internal shorthand, as it were-and subject these to the particular scrutiny facilitated by a selfreflective comparative perspective. It is our conviction that the concepts, theories, and methods employed by both lawyers and socio-legal scholars are intrinsically linked to the histories of both of their disciplines, and that this becomes especially apparent when comparing two countries with diverging trajectories. Socio-legal and legal thinking have always mirrored each other more or less explicitly, even in a jurisdiction like Germany where the doctrinal project is still effectively hegemonic. ${ }^{8}$

Hendry and Creutzfeldt were inspired to hold the Berlin workshop by an earlier SLSA-funded UK-French 2018 event in Paris. ${ }^{9}$ They contacted Boulanger, who had been involved in recent efforts to strengthen the socio-legal scene in Germany, and whose atypical position, a social scientist working at a German law faculty, provided a fresh perspective. While all three scholars had separate and overlapping networks within law and society scholarship, it quickly became apparent that connections across those communities were limited. British and German scholars were often more likely to meet, whether intentionally or coincidentally, at a Law and Society Association annual meeting in the U.S. rather than in an academic event closer to home. ${ }^{10}$ It further transpired that there were notable differences in the development of the research field; differences that were often awkward to track as a result of research and scholarship being undertaken under varied banners, namely "socio-legal studies," "law and society," "Rechtssoziologie/sociology of law," or "Interdisziplinäre Rechtsforschung (interdisciplinary research on law)." most importantly in terms of the aims of this Special Issue, the lack of comparative literature became increasingly evident. ${ }^{12}$ Given that this initial mapping seemed to present several gaps, we were curious to see who would respond to the workshop call for articles that asked for contributions with a specifically cross-national perspective on methods and theories in socio-legal research.

This current Special Issue showcases selected responses to our workshop call, with these selections being indicative of the varied positions in both countries. Some immediately apparent divergences arose in terms of contributors. For example, there were more doctoral candidates from the UK, and a slight gender imbalance towards female participants. In terms of subject matter, submissions from British scholars focused more on methods and substantive research questions, while the submissions generated via the German networks took a more historical and grand-theoretical approach. More broadly, and notable in light of our meta-comparative approach, comparative issues were less well represented than anticipated; indeed, throughout the workshop it became increasingly apparent that comparative research on socio-legal studies lacks both a shared conceptual vocabulary and a literature base. It is these lacunae that this Special Issue will start to fill.

\footnotetext{
${ }^{8}$ As compared to the UK, where some observers consider it in "its final death throes." Anthony Bradney, Law as a Parasitic Discipline, 25 J. L. \& SoC'Y 71 (1998).

${ }^{9}$ The workshop explored the methods, traditions, and theories of socio-legal studies in France and the UK, reflecting on what "socio-legal studies in context" means for research traditions and forms of knowledge produced. Edward Dove, What Can Socio-Legal Studies Contribute to Medical Law? Thoughts From a Workshop in Paris, SLSA Blog (2018),

${ }^{10}$ This is probably true for any two European countries picked at random, there is no European forum for socio-legal research that could remotely rival the membership base or the LSA and the corresponding size of its annual conferences.

${ }^{11}$ SusANne BAER, RECHTSSOZIOlOgIE: EINE EINFÜHRUNG IN DIE INTERDISZIPLINÄRE RECHTSFORSCHUNG (3d ed. 2017); THE Handbook of Law and Society (Austin Sarat \& Patricia Ewick eds., 2015); Routledge Handbook of Socio-Legal Theory AND Methods (Naomi Creutzfeldt, Marc Mason \& Kirsten McConnachie eds., 2020).

${ }^{12}$ There have been efforts to map individual disciplinary histories, for example a the ongoing Journal of Law \& Society series that has so far covered Aotearoa/New Zealand, Canada, France, Germany and most recently Poland, or country reports in the International Journal of Law in Context, including reports on Germany, France, Japan or Denmark.
} 


\section{Part Two: Differences and Challenges}

The first challenge of this comparative project is that the academic study of law differs significantly in both countries. Leaving aside substantive and doctrinal differences, our focus is on the different epistemological legal research traditions represented by each country's academic culture. While one adopts a normative perspective, the other's perspective is more empirical, and crossover is comparatively minimal. To make things even more complex, on closer inspection, it turns out that the boundaries between the "normative/doctrinal" and "empirical/socio-legal" are differently drawn in both countries, and the historical and present relationship between the two traditions also differs significantly. It is therefore necessary to develop a vocabulary that is capable of capturing not only the shifting boundaries of "legal" and "nonlegal" approaches to law, ${ }^{13}$ but also what is distinct in the "doctrinal" study of law against which sociological approaches have often set themselves in opposition. ${ }^{14}$

The second challenge is that, as previously mentioned, very little comparative scholarship exists on law and society studies in both countries. This situation is further aggravated by the fact that only scant data is available on research environments and communities upon which comparative analyses can be based. The situation is somewhat better in the UK, as several reports on legal education have been published, which make recommendations on socio-legal teaching and research. ${ }^{15}$ In Germany, one report on legal scholarship, published in $2012,{ }^{16}$ mentions the importance of non-doctrinal approaches as "foundational" subjects in legal education, but otherwise does not contain any data of relevance to the current investigation.

A third challenge is that German-UK networks of socio-legal research collaboration and shared information are currently still in their infancy. In the past, there have only been a few common research projects and little exchange about academic events, a situation likely caused by the language barrier. By contrast to this lack of direct UK-German collaboration and interaction, the Law and Society Association (LSA) annual conference in the U.S. has provided a convenient and often fertile ground for networking, being attended by scholars from both countries; the UK's SocioLegal Studies Association (SLSA) annual conference seems to be less well known within German academia. And a final point to note in terms of obstacles to potential collaboration is that German remains the main language of publication of German scholarship, which has the effect of (de)limiting the audience, reinforcing the academic status quo, and arguably restricting innovation. Indeed, it was with a view to addressing these issues that the German Law Journal came into being as the premier vehicle for English-language scholarship focusing on German, European, and international law and jurisprudence.

An interesting sidebar with respect to research collaboration between Germany- and UK-based scholars is that, unknown to the other, two of the present editors were involved in producing textbooks on socio-legal approaches in the $\mathrm{UK}^{17}$ and Germany respectively. ${ }^{18}$ The different foci

\footnotetext{
${ }^{13}$ See, e.g., Reza Banakar, Law Through Sociology's Looking Glass: Conflict and Competition in Sociological Studies of Law, in The ISA Handbook In Contemporary Sociology 58 (Ann Denis \& Devorah Kalekin-Fishman eds., 2009) (enumerating different forms of socio-legal research).

${ }^{14}$ Christian Boulanger, The Comparative Sociology of Legal Doctrine: Thoughts on a Research Program, in this issue.

${ }^{15}$ Hazel G. Genn, Martin Partington \& Sally Wheeler, Law in the Real World: Improving Our Understanding of How Law Works: Final Report and Recommendations (2006); Fiona Cownie, Legal Academics: Culture and IDENTITIES (2004); Fiona Cownie \& Anthony Bradney, An Examined Life: Research into University Legal Education in the United Kingdom and the Journal of Law and Society, 44 J. L. \& Soc'y S129 (2017).

${ }^{16}$ Wissenschaftsrat, Perspektiven DER Rechtswissenschaft In DEUTSCHLAND: Situation, ANALYSEN, EMPFEHLUNGEN (2012), translated in German Council of Science and Humanities, Prospects of Legal Scholarship in Germany: CURRENT Situation, AnAlyses, Recommendations (2012), https://www.wissenschaftsrat.de/download/archiv/255812_engl.pdf;jsessionid=B2B960E93BD907264DFB20E7E54467F3.delivery1-master?_blob=publicationFile\&v=3.

${ }^{17}$ Routledge Handbook of Socio-Legal Theory and Methods, supra note 11 .

${ }^{18}$ INTERDISZIPLINÄRE RECHTSFORSCHUNG: EINE EINFÜHRUNG IN DIE GEISTES- UND SOZIALWISSENSCHAFTLICHE BEFASSUNG Mit DEM Recht UND SEINER PraXis (Christian Boulanger, Julika Rosenstock \& Tobias Singelnstein eds., 2019).
} 
and choices of these volumes are worthy of note here, as each textbook reflects the current state of knowledge as well as the ambition and authority of the discipline in very different ways. The German textbook is clearly embedded in a "sociology of law" tradition and maps a very disparate and fragmented research landscape. Its aim is to contribute to an emerging disciplinary identity after what has been a long period of stagnation. The chapters reflect the fact that socio-legal research still lacks, among other things, a firm institutional base, clear career paths, and established curricula. By comparison, the Routledge Handbook builds on and reflects an established discipline with academic protagonists, discrete schools of thought, different career stages, and systematic teaching on research methodology from socio-legal scholars around the world.

\section{Part Three: Contributions to this Special Issue}

In light of the breadth of issues raised by the initial mapping, an important consideration for us has been: how can we respond to these challenges and study these differences in a systematic way? We have thus identified four core strands that appear consistently throughout this mapping and, indeed, this Special Issue, and which are worthy of flagging in terms of the specific questions that they provoke. These are:

1. Legal Culture: What are the different trajectories of academic and legal cultures in Germany and the UK? Is there a typical pathway into and through law and society research?

2. Scholarship: Can patterns of law and society scholarship (education/ training/ mobility/language competence/supervision) be identified? How influential are kinship connections? What theoretical traditions have been prevalent, and which ones are less visible?

3. Pedagogy: How do pedagogic practices, learning, and teaching differ in Germany and the UK? Is law and society taught as theory, practice, or both? To what extent does canonical socio-legal theory appear in contemporary law and society research and student education?

4. Institutions: In what ways do institutional structures that influence law and society research and education in the UK and Germany differ? Are these academic, professional, or both?

These four strands, which will be discussed in Part Four of this introduction, should be borne in mind throughout the Special Issue. The issue itself is structured into three sections: background and development, historical socio-legal perspectives, and contemporary socio-legal perspectives. It opens with Stefan Machura's comprehensive comparative account of the status quo in Germany and the UK. Machura sets himself the task of identifying and scrutinizing the key stages of development in both countries' socio-legal scholarly traditions. From the perspective of a Wales-based and German-trained scholar, Machura's comparison identifies the differing contours of what is alternatively known in English as socio-legal studies, law and society, and the sociology of law, the salient differences between these, and the extent to which they can be said to overlap. In terms of the subject's innate interdisciplinarity, Machura observes that particularly law schools within the UK have been more effective in accommodating this, while in Germany the disciplines of law and sociology are, whether intentionally or accidentally, very far apart.

Tanja Herklotz continues the comparative endeavor, although her focus rests explicitly on the specifics of comparing different socio-legal cultures of research and scholarship. Herklotz notes that the selection of what to compare in this sense is particularly salient, and cites the important comparators for this task as being: institutions, publications, scholars, and teaching. Herklotz offers a range of research questions that socio-legal scholars can draw upon when engaging in comparative projects. Further to this, Herklotz probes the "how" of such comparative work, outlining and critiquing several interdisciplinary methodological approaches and tools.

This background and development section continues in a self-reflective vein with Ulrike Schultz's fascinating account of gender in German socio-legal research and teaching. Drawing on her personal 
experience, Schultz outlines and analyses not only the socio-legal issue of gender equality, but also the challenges in, and obstacles to, undertaking such research within Germany's legal-academic culture. By blending contextualized historical developments, such as gender equality legislation and increasingly permissive social norms, with her situated personal reflections on female professorial appointments and gender-related content in university teaching and curriculums, Schultz provides a unique and nuanced view of value to contemporary scholars of gender equality.

Concluding this section, in Christian Boulanger's article exploring the minefield of undertaking comparative research on legal doctrine, or Rechtsdogmatik, Boulanger notes that, while currently scholars in many different disciplinary areas are studying doctrinal aspects of law both normatively and empirically, an interdisciplinary and cross-national field of research has yet to take shape. In Germany, the sociology of law has, in Boulanger's view, been very reticent about analyses of legal doctrine, which it has regarded sometimes with suspicion, and as part of the "law on the books," in unfavorable contrast with the "law in action." Boulanger argues that the comparative study of legal doctrine as an institutionally legitimated social practice helps to understand how one is translated into the other, which is also relevant for evaluating the role of legal scholarship in democratic societies. For Boulanger, the almost diametrically opposed traditions of doctrinal analysis in Germany and the UK provide a fertile ground for comparative analysis. Using examples from German research, Boulanger's article contributes theoretical and methodological perspectives to the research agenda of the currently emerging socio-legal study of legal doctrine.

The articles in the next section on historical socio-legal perspectives take a somewhat broader approach. Remaining largely sectoral in focus, however, Rebecca Zahn, Klaas-Henrik Eller, and Ioannis Kampourakis provide comparative analyses of, respectively, historical socio-legal labor law scholarship, the empirical study of legal doctrine, the development of socio-legal research on the law of contract, and the different methodological and epistemological ideas to be found in different empirical approaches to law. Opening this section is Zahn's article, at the forefront of which is the recognized challenge posed by comparative labor law history, a largely neglected field that — in both Germany and the UK—-has lacked those galvanizing academic debates as to the best way for it to be undertaken. In addition to Zahn's comprehensive and insightful account of this field in both countries, Zahn argues explicitly in favor of a methodology called "minor comparativism." Although at its heart still fundamentally comparative, this method makes the deliberate attempt to include the marginalized or minority foreign view by intentionally adopting "the perspective of those who remain foreign." 19

By looking at contract law, Eller is able to survey a research topic that also connects a large variety of disciplinary inquiries from both normative and analytical perspectives, each with a long history of scholarly interest. As Eller notes, the study of contract is torn between the universality of the contract as a form and the specificity of its practice in different contexts. In particular, the way contract law has dealt with the "relational" character of contracts has been very different; for example, the fact that contracts cannot be detached from the social context in which they exist without creating normative or analytical problems. The article contrasts developments in contract law in the UK and US with those of Germany and finds that the variations are partly explained by the fact that the reception of legal realism varied widely. In the common law countries, the reception led to more interdisciplinary perspectives on contract law, whereas in Germany, realist thinking did not take root in post-war Germany's contract law doctrine. Eller concludes his article with thoughts on how these developments play out in the case of transnational contract law. He finds that despite the turn to "reflexive" law, transnational contract law scholarship is not characterized by truly interdisciplinary debates.

Kampourakis' article concludes this section by comparing two different sociological approaches to law - that is, empirical socio-legal studies and the "grand theory" of autopoietic

\footnotetext{
${ }^{19}$ Rebecca Zahn, Finding New Ways of "Doing" Socio Legal Labor Law History in Germany and the UK: Introducing a "Minor Comparativism," in this issue.
} 
social systems - in terms of transnational private regulation, an "increasingly important aspect of legal and social ordering under conditions of globalization." ${ }^{20}$ Drawing attention to the effects that adopting epistemologically different theoretical approaches has upon the motivations, structuring, and results of such studies, Kampourakis then leads the more macro argument that insights into the field's developmental divergence in Germany and the UK can be gleaned from each country's law and society community, exhibiting a notable preference for one of these respective sociological approaches to the study of law.

The final section on contemporary socio-legal perspectives showcases new methodological approaches to socio-legal research. The articles in this section employ different perspectives, interdisciplinary approaches, and theories, considering legal design, urban law, and what it means to undertake socio-legal research "politically." Perry-Kessaris' article introduces the idea of legal design, that is, consideration of how the outlooks and tools characteristically associated with design can be oriented towards legal thinking and matters. Perry-Kessaris argues in favor of a sociologically-informed approach to both the theory and application of principles of legal design, stacking on top of these initial considerations a further requirement also to include sociological insights. With both law and design being social phenomena, Perry-Kessaris makes the case, referencing influential Anglo-German literature and practices, for the conceptualization of legal design as a form of social relations. Perry-Kessaris' article asks the question: "What would a sociologically-informed approach to researching legal design look like conceptually, empirically, and normatively?"21

Layard draws our attention to an area of scholarship underexplored in both countries' law and society scholarship: urban law. In proposing how such research can be undertaken, Layard advocates grasping legal opportunities to analyze urbanism comparatively as a socio-legal task. Adopting the leitmotiv of the cross-discipline, Layard shifts focus of inquiry from law to society. While underdeveloped across Europe, urban law scholarship in North America includes analyses of, for example, the relationships between national and state government, as well as individual legal aspects of housing, zoning, licensing, sustainability, consumer protection, poverty, race, and data law. Layard calls for scholars to follow Auby's ground-breaking Droit de la ville, where Auby synthesizes materials for lawyers and non-lawyers alike. Drawing on Andreas PhilippopoulosMihalopoulos' suggestion of understanding a city as a lawscape, thereby integrating elements of the law with elements of the city, Layard describes a rich set of methods to explore urban law, drawing on doctrinal analysis, empirical observations, interviews, ethnographies, quantitative and mapping exercises, as well as contextual policy analysis.

Concluding this section, and indeed, this Special Issue, Mant's article puts into practice the kind of self-reflection discussed by both Herklotz and Schultz, recognizing how socio-legal researchers - specifically early-careers researchers in this particular case-must work politically in terms of reflecting on their own theoretical and methodological selections. This bigger-picture approach thus demands not only a commitment to self-reflection within a research project, but also within the discipline more broadly. Mant notes that, as is the case in her own study of litigants-in-person (LIPs) in family courts in England and Wales, the composite application - to a single issue-of different approaches that, while independently insightful, may appear irreconcilable, offers a genuinely fertile tension. While Mant's socio-legal study blends feminist legal theory with insights drawn from Bourdieu and Latour's Actor-Network Theory, the contribution of this article to the Special Issue lies in its recognition of how the myriad different tools available to socio-legal researchers can and even should interact, even in light of their apparent incoherence. That this article focuses on the willingness of early-career researchers to undertake this kind of blended

\footnotetext{
${ }^{20}$ Ioannis Kampourakis, Empiricism, Constructivism, and Grand Theory in Sociological Approaches to Law: The Case of Transnational Private Regulation, in this issue.

${ }^{21}$ A. Perry-Kassaris, Making Socio-legal Research More Social by Design: Anglo-German Roots, Rewards, and Risks, in this issue
} 
research, moreover, highlights how different supervision and training practices have an enormous impact upon the development and ambit of socio-legal studies more generally.

\section{E. Part Four: Stronger Ties}

This Special Issue is a foundational part of an ongoing ambitious project to bring together socio-legal communities and to forge stronger ties between them. Our focus is on the UK and Germany, as these are the socio-legal spaces we operate within. This connected space has, we believe, huge potential to grow and to develop. The four strands mentioned above that we identify as running throughout this Special Issue correspond to four focal areas. It is through the targeted exploration of these that we can better understand the composition and operation of socio-legal spheres in the two countries. This collaborative socio-legal work will continue, and the uncertainties provoked by the COVID-19 pandemic and looming Brexit mean that it is ever more important to strengthen connections between jurisdictions and intellectual communities. The next generation of socio-legal scholars has enormous potential, and there is no better time at which to recognize and dismantle obstacles to cross-community action and interaction, to identify synergies, to strengthen ties, and to strengthen the socio-legal community beyond narrow national academic boundaries.

Cite this article: Hendry J, Creutzfeldt N, and Boulanger C (2020). Socio-Legal Studies in Germany and the UK: Theory and Methods. German Law Journal 21, 1309-1317. https://doi.org/10.1017/glj.2020.83 